\title{
Pengenalan Bentuk dan Pola Suara bagi Anak Anak Penyandang Tuna Rungu
}

\author{
Oleh: \\ Ariyono Setiawan
}

\author{
Program Studi D3 Teknik Telekomunikasi dan Navigasi Udara \\ Politeknik Penerbangan Surabaya \\ Jemur Andayani I/73 Wonocolo Surabaya 60236 \\ Telp. (031)8410871, Fax. (031) 8490005 \\ Email : rmaryo4u@gmail.com
}

\begin{abstract}
IInability to speak for the Deaf child is a distinctive characteristic that makes it different from normal children. Children with normal hearing understand the language through hearing in the months before they start talking. Speech recognition or recognition of voice patterns in children Deaf as search forms grades suitability and appropriateness. the type of sound is a development from techniques and systems that enable the computer to accept input in the form of patterns spoken word so on get the value of the type of words approaches, and can be understood. This study proposes a solution in Method utilizes biometrics to recognize the type of sound patterns deaf children who will be in the skewer with the sound of a normal child. Biometric methods used in digital signal processing (in this case sound) in the form of discrete biometrics refers to the automatic identification of humans by psikological or basic human characteristic sound
\end{abstract}

Keyword : Biomedical, Voice Signal, Sound pattern, Deaf

\section{PENDAHULUAN}

Komunikasi merupakan kebutuhan manusia yang sangat penting. Komunikasi dibutuhkan untuk memperoleh atau memberi informasi dari atau kepada orang lain. Dalam kehidupannya, manusia selalu melakukan kegiatan komunikasi sebagai bukti kesadaran akan keberadaannya, yaitu mengadakan aksi dan ber-reaksi atas stimulun yang datang padanya. Selagi ia masih hidup, manusia selalu melakukan berbagai kebutuhannya, dalam hal ini kegiatan komunikasi adalah yang paling banyak dilakukan. Manusia sebagai makhluk sosial harus hidup bermasyarakat. Semakin besar suatu masyarakat, berarti semakin banyak manusia yang dicakup, dan cenderung akan semakin banyak masalah yang timbul, akibat perbedaanperbedaan yang terdapat diantara manusia-manusia tersebut. Percakapan manusia dapat dikatakan komunikatif apabila kedua-duanya selain mengerti bahasa yang digunakan juga mengerti makna dari bahan yang dibicarakan. Melalui komunikasi manusia dapat menyampaikan informasi, pikiran, pengalaman, pendapat, perasaan, pengetahuan maupun harapannya. Ketidak mampuan bicara pada anak Tuna Rungu merupakan ciri yang khas yang membuatnya berbeda dengan anak normal. Anak yang normal pendengarannya memahami bahasa melalui pendengarannya dalam waktu berbulan-bulan sebelum mereka mulai berbicara. Tuna Rungu atau gangguan dengar dalam kedokteran adalah kondisi fisik yang ditandai dengan penurunan atau ketidak mampuan seseorang untuk mendengarkan suara. Sedangkan Bisu adalah ketidak mampuan seseorang untuk berbicara. Bisu disebabkan oleh gangguan pada organ-organ seperti tenggorokan, pita suara, paru-paru, mulut, lidah, dsb. 


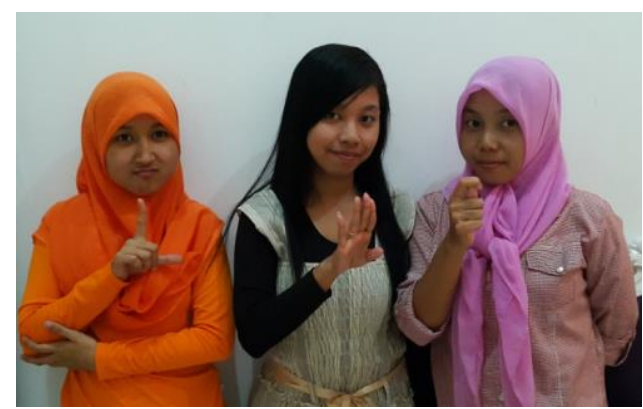

Gambar 1. Pengunaan Bahasa Isyarat Pada Anak Tuna Runggu

Kebanyakan anak Tuna Rungu menggunakan isyarat sebagai cara mereka berkomunikasi. Ini karena telinganya tidak dapat menangkap suara percakapan. Bagaimana jika mereka mengucapkan kata sehingga setiap kata yang keluar pasti tidak akan jelas, atau bahkan tidak mengeluarkan suara sama sekali.

Murni Winarsih (2007: 23), menyatakan Tuna Rungu adalah seseorang yang mengalami kekurangan atau kehilangan kemampuan mendengar baik sebagian atau seluruhnya yang diakibatkan oleh tidak fungsinya sebagian atau seluruh alat pendengaran, sehingga anak tersebut tidak dapat menggunakan alat pendengarannya dalam kehidupan sehari-hari. Hal tersebut berdampak terhadap kehidupannya secara kompleks terutama pada kemampuan berbahasa sebagai alat komunikasi yang sangat penting. Gangguan mendengar yang dialami anak Tuna Rungu menyebabkan terhambatnya perkebangan bahasa anak, karena perkembangan tersebut, sangat penting untuk berkomunikasi dengan orang lain. Berkomunikasi dengan orang lain membutuhkan bahasa dengan artikulasi atau ucapan yang jelas sehingga pesan yang akan disampaikan dapat tersapaikan dengan baik dan mempunyai satu makna, sehingga tidak ada salah tafsir makna yang dikomunikasikan. 1 hingga 2 dari 1000 bayi yang baru lahir mengalami gangguan pendengaran. Universal newborn hearing screening (UNHS) merupakan alat yang digunakan untuk mengidentifikasi kemungkinan kehilangan pendengaran pada bayi yang baru lahir. Screening awal penting dilakukan untuk mengetahui apakah bayi yang baru lahir mengalami gangguan pendengaran atau tidak. Hal ini sangat berguna untuk pemberian tindakan selanjutnya, seperti mencari tahu penyebab dan kemungkinan diberikan penggunaan alat bantu dengar. Umumnya, orang dapat mendengar jika telinga dapat menangkap suara dengan frekuensi bunyi 20 s.d. 20.000hertz (Hz). Dalam ukuran decibel (dB) atau intensitas bunyi, volume terkecil yang masih dapat didengar memiliki intensitas sebesar $0 \mathrm{~dB}$. Sebagai gambaran, bisikan umumnya memiliki intensitas $30 \mathrm{~dB}$, percakapan sehari-hari berkisar antara 30 sampai $60 \mathrm{~dB}$, dan volume suara pada konser musik rock bisa mencapai $140 \mathrm{~dB}$.

Kehilangan pendengaran memiliki rentang dari mild (ringan) hingga profound (sangat parah), secara umum dapat digolongkan sebagai berikut :

- Mild : 20-40 dB

- Moderate : 41-60 dB

- Severe : 61-90 dB

- Profound : > $>00 \mathrm{~dB}$

Secara klinis, dalam arti yang luas, Tuna Rungu meliputi segala bentuk kehilangan pendengaran, dari samar-samar hingga tingkat paling akut. Tuna Rungu dipandang sebagai sebuah gangguan atau ketidak mampuan yang menyebabkan masalah sehingga perlu dicegah atau diatasi. Tuna Rungu adalah sebuah kondisi yang alamiah, yang harus dijaga dan dihormati. Kebanyakan orang mengira bahwa mengalami gangguan pendengaran lebih baik dibandingkan gangguan penglihatan. Nyatanya, orang Tuna Rungu memiliki kesulitan lebih besar dibandingkan orang yang mengalami kebutaan. Kesulitan ini umumnya lebih banyak dalam hal penyesuaian. Hal ini terjadi karena hilangnya fungsi pendengaran bisa membuat orang sulit untuk memahami dan berbicara gerak bibir. Dalam kehidupan sehari-hari, orang cenderung berkomunikasi dengan bahasa lisan. Jika tidak dapat menguasai dua hal ini dengan baik, dapat 
dipastikan bahwa proses belajar seseorang akan terhambat. Untuk berbicara dengan penyandang Tuna Rungu, kita harus menggunakan ASL American Sign Language, pengkodean huruf dengan jari yang sudah distandarkan secara internasional agar semua orang didunia mempunyai persepsi yang sama dengan kodenya. Sebagaimana yang kita ketahui bahwa anak yang memiliki gangguan pendengaran/tuna rungu pasti akan memiliki kesulitan berkomunikasi secara verbal. Akan tetapi bila anak tuna rungu ditangani dengan tepat, konsisten dan sistematis maka kesulitan berkomunikasi secara verbal bisa ditanggulangi. Hal yang paling sulit dipelajari oleh anak tuna rungu adalah belajar mendengar,maka pendekatan yang diberikan pada anak tuna rungu bukan hanya melalui sensor auditory (pendengaran) tapi juga mengikut sertakan sensor visual dan taktil kinestetik (rasa raba).

Menurut Joseph Bram "a language is a structured system of arbitary vocal symbols by means of which members of social group interact" yang berarti "bahasa adalah suatu system yang berstruktur dari symbol-simbol bunyi arbiter yang dipergunakan oleh para anggota suatu kelompok sosial sebagai alat bergaul satu sama lain." Didalam aturan secara linguistik, unsur bahasa dibagi atas tiga bagian, meliputi isi, bentuk dan penggunaan. Dimana kita tahu dalam berkomunikasi secara verbal sehari-hari kita sudah pasti akan menggunakan ketiga unsur tersebut.

Ditinjau dari bidang fonologi Kata dikelompokan atas vocal(vokoid) dan bunyi konsonan (kontoid). Dan dalam bahasa Indonesia sendiri bunyi vocal terbagi atas 6 bunyi yaitu /a/,/i/,/u/,/e/,/o/,dan /?/ .Sedangkan bunyi konsonan ditentukan oleh cara pengucapan (manner of articulation) dan titik pengucapan (point of articulation). Ditinjau dari cara pengucapan,bunyi konsonan digolongkan dalam :

1. Konsonan plosif : /t/,/d/,/p/,/b/,/k/,/g/

2. Konsonan frikatif : /f/,/s/,/z/

3. Konsonan afrikat $: / \mathrm{c} /, \mathrm{j} /$

4. Konsonan getar : /r/

5. Konsonan nasal :/n/

6. Konsonan semi-vokal : /w/

7. Konsonan lateral : /1/

Berdasarkan titik artikulasi,bunyi konsonan digolongkan menjadi :

1. Konsonan bilabial : /p/,/b/,/m/

2. Konsonan labio dental : /f/,/v/,/w/

3. Konsonan apiko dental : /t/

4. Konsonan apiko alveolar : /n/,/l/,/r/

5. Konsonan apiko palatal : /d/

6. Konsonan lamino alveolar : /s/,/z/

7. Konsonan medio palatal : /c/,/g/,/ny/

8. Konsonan dorso velar: /k/,/g/,/ng/,/x/

Pada umumnya bagi anak tuna rungu suara Ucapan vocal lebih mudah diucapkan daripada konsonan. Untuk konsonan ada pembagian beberapa karakter berdasarkan asal keluarnya huruf

1. konsonan bilabial $(\mathrm{p} / \mathrm{b} / \mathrm{m})$ merupakan konsonan bibir

contoh : p papa apa map

b babi aba bab

m mama oma bom

2. konsonan dental $(\mathrm{t} / \mathrm{d} / \mathrm{n})$ seperti halnya bilabial

3. konsonan langit-langit lembut $(\mathrm{k}, \mathrm{g}, \mathrm{ng})$ 
Besar kecil kehilangan pendengaran sangat berpengaruh terhadap kemampuan komunikasinya dalam kehidupan sehari-hari, terutama bicara dengan artikulasi yang jelas dan benar. Bicara dengan artikulasi yang jelas akan mempermudah orang lain memahami setiap pesan yang disampaikan

Pada penelitian ini memanfaatkan beberapa metode untuk pengenalan jenis dari pola suara anak tuna rungu yang akan di cocokan dengan suara anak normal. Metode Biometrik digunakan dalam pemrosesan sinyal digital dalam bentuk diskrit dan digunakan sebagai pemroses awal dari pengolah data untuk mendapatkan nilai kecocokan dari setiap sampel suara yang di dapat. Biometrik mengacu pada identifikasi secara otomatis terhadap manusia berdasarkan psikological atau karakteristik pola suara dasar manusia

Untuk berbicara dengan penyandang Tuna Rungu, kita harus menggunakan ASL American Sign Language, pengkodean huruf dengan jari yang sudah distandarkan secara internasional agar semua orang didunia mempunyai persepsi yang sama dengan kodenya
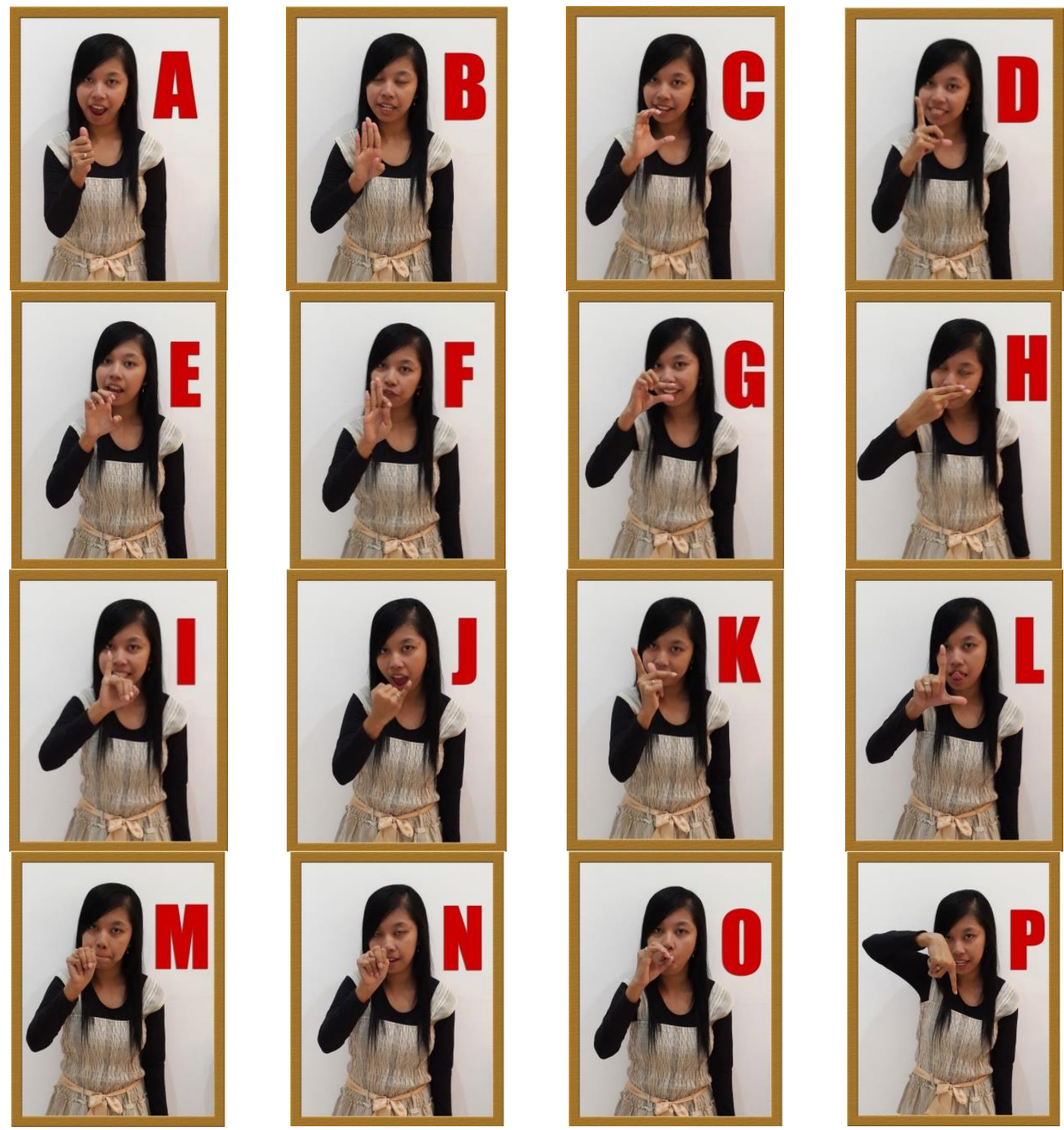

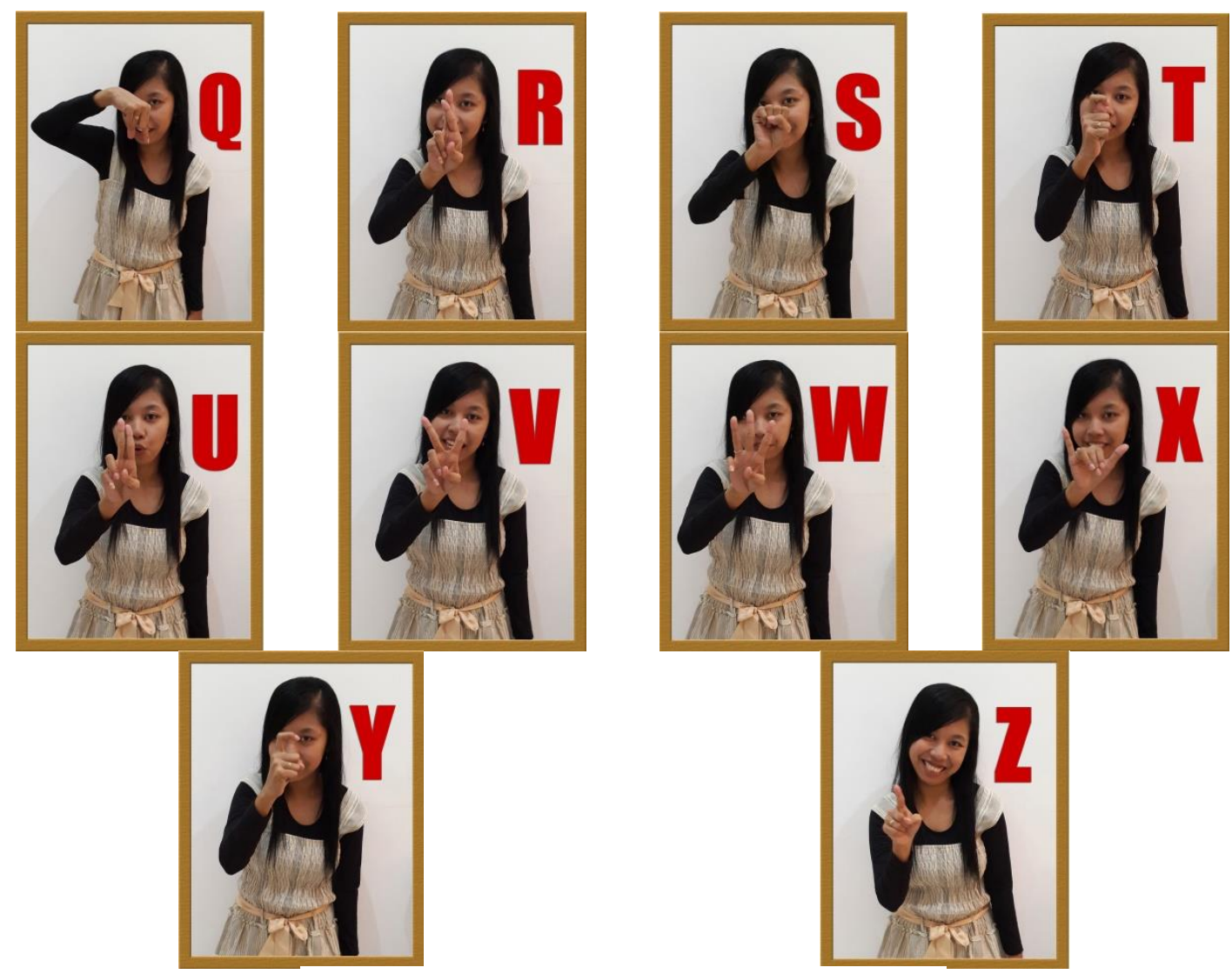

Gambar 2. ASL( American Sign Language)

\section{PERANCANGAN SISTEM}

Keunikan bentuk pola suara yang di hasilkan oleh anak tuna rungu merupan bentuk artikulasi vocal dari konsonan bibir, dental, dan langit-langit suara. Pencarian nilai kecocokan dari setiap sampel suara yang di dapat akan memberikan manfaat sehingga setiap kata dapat di pahami
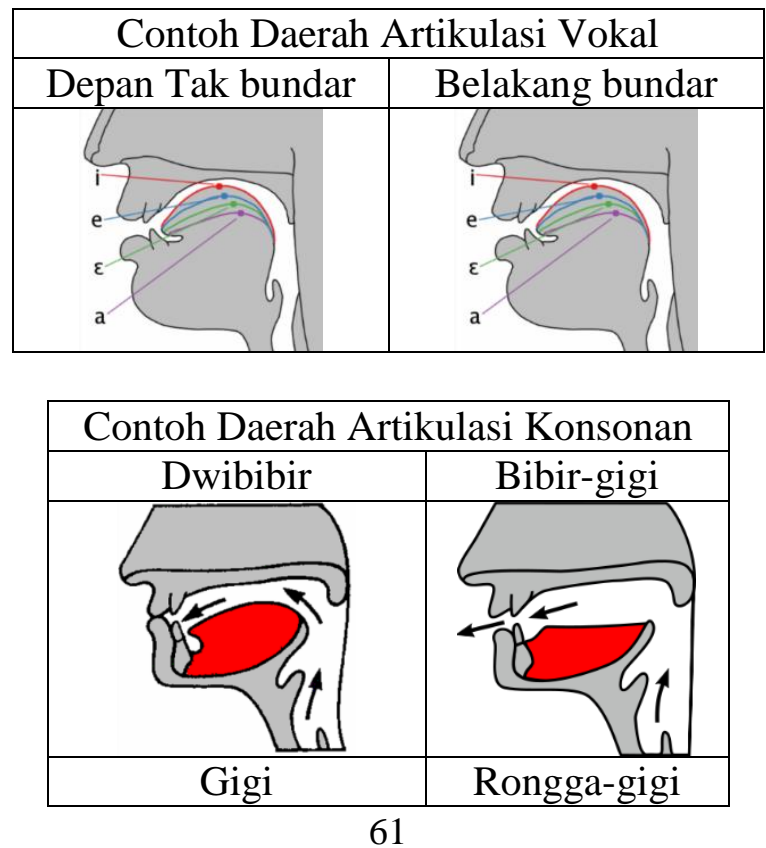


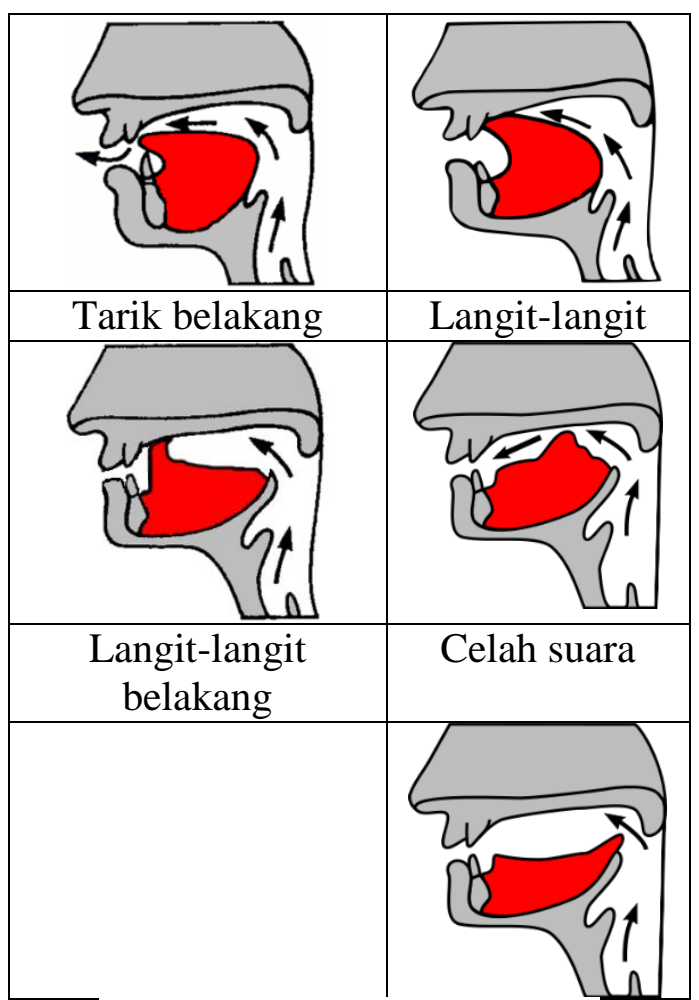

Gambar 3. Daerah Artikulasi

1. Manfaat yang diperoleh dari pelaksanaan penelitian ini ndapat menghasilkan formulasi dan desain awal yang dapat diaplikasikan dalam keperluan biometrik khusunya pengenalan pola suara anak tuna rungu. Untuk selanjutnya dari formulasi awal ini dapat di temukan standar dari pengenalan pola suara anak tuna runggu sehingga setiap suara yang di ucapkan dapat lebih mudah di pahami atau di mengerti.

2. Keunikan jenis suara yang di hasilkan para penyandang Tuna Rungu merupakan jenis suara yang khusus, yang di hasilkan dari setiap pergerakan bentuk mimik mulut yang kesemuanya juga mempunya nilai kalibrasi vocal dan konsonan dapat di analisa

3. Pola pengenalan suara dari penelitian yang di hasilkan di harapkan dapat memberikan gambaran bahwa ada beberapa kesamaan bentuk pola suara yang dihasilkan antara jenis suara orang normal dan jenis suara para penyandang Tuna Rungu yang berbeda adalah dari tingkat penekanan suara

4. di harapkan pada penelitian selanjutnya dapat memberikan pengembangan implementasi setiap kata yang di ucapkan para penyandang Tuna Rungu dapat menjadi kata yang mudah di pahami dan di mengerti pengucapannya

Tabel 1. Persamaan Dan Perbedaan Dengan Penelitian Sebelumnya

\begin{tabular}{|c|l|l|}
\hline NO & \multicolumn{1}{|c|}{ PERSAMAAN } & \multicolumn{1}{|c|}{ PERBEDAAN } \\
\hline $\mathbf{1}$ & $\begin{array}{l}\text { Menggunakan beberapa metode yang } \\
\text { sama }\end{array}$ & $\begin{array}{l}\text { Obyek Penelitian adalah pola suara } \\
\text { anak tuna rungu }\end{array}$ \\
\hline $\mathbf{2}$ & $\begin{array}{l}\text { Obyek Penelitian adalah pola suara anak } \\
\text { normal }\end{array}$ & \\
\hline $\mathbf{3}$ & Pengenalan Pola Suara & \\
\hline
\end{tabular}




\section{CARA KERJA SISTEM}

Pengenalan ucapan atau pengenalan pola suara sebagai bentuk pencarian nilai kecocokan dan ketepatan jenis suara adalah suatu pengembangan teknik dan sistem yang memungkinkan komputer untuk menerima masukan berupa kata yang diucapkan. Teknologi ini memungkinkan suatu perangkat untuk mengenali dan memahami kata-kata yang diucapkan dengan cara digitalisasi kata dan mencocokkan sinyal digital tersebut dengan suatu pola tertentu yang tersimpan dalam suatu perangkat. Setiap yang diucapkan diubah bentuknya menjadi sinyal digital dengan cara mengubah gelombang suara menjadi sekumpulan angka yang kemudian disesuaikan dengan kode-kode tertentu untuk mengidentifikasikan kata-kata tersebut. Hasil dari identifikasi kata yang diucapkan dapat ditampilkan dalam bentuk teks.

Pengenalan ucapan dalam perkembangan teknologinya merupakan bagian dari pengenalan suara (proses identifikasi seseorang berdasarkan suaranya). Pengenalan suara sendiri terbagi menjadi dua, yaitu pengenalan pembicara (identifikasi suara berdasarkan orang yang berbicara) dan pengenalan ucapan (identifikasi suara berdasarkan kata yang diucapkan). Speech Recognition juga merupakan sistem yang digunakan untuk mengenali perintah kata dari suara manusia dan kemudian diterjemahkan menjadi suatu data yang dimengerti oleh computer. Parameter yang dibandingkan ialah tingkat penekanan suara yang kemudian akan dicocokkan dengan template database yang tersedia.

Pada penelitian ini memanfaatkan metode biometrik untuk pengenalan jenis dari pola suara anak tuna rungu yang akan di cocokan dengan suara anak normal. Metode Biometrik digunakan dalam pemrosesan sinyal digital (dalam hal ini suara) dalam bentuk diskrit.

Secara umum, pengenalan pola kata memproses sinyal suara yang masuk dan menyimpannya dalam bentuk digital. Hasil proses digitalisasi tersebut kemudian dikonversi dalam bentuk spektrum suara yang akan dianalisa dengan membandingkan dengan template suara pada database sistem. Sebelumnya, data suara masukan dipilah-pilah dan diproses satu per satu berdasarkan urutannya. Pemilahan ini dilakukan agar proses analisis dapat dilakukan secara paralel. Pengenalan pola kata mengunakan metode biometric, yaitu proses komputer mengenali apa yang diucapkan seseorang berdasarkan intonasi suara yang dikonversi ke dalam bentuk digital print. Biometric digunakan untuk identifikasi dan verifikasi. Identifikasi ialah mengenali identitas subyek, dilakukan perbandingan kecocokan antara data biometric subyek dalam database berisi record karakter subyek. Sedangkan verifikasi adalah menentukan apakah subyek sesuai dengan apa yang dikatakan dari sumber suara.

Biometrik merupakan suatu metoda untuk mengenali manusia berdasarkan pada satu atau lebih ciriciri pola suara unik. Biometric Recognition atau biasa disebut dengan Sistem pengenalan biometric mengacu pada identifikasi secara otomatis terhadap manusia berdasarkan psikological atau karakteristik tingkah laku manusia

Metode Hidden Markov Model mulai diperkenalkan dan dipelajari pada akhir tahun 1960, metode yang berupa model statistik dari rantai Markov ini semakin banyak dipakai pada tahun-tahun terakhir terutama dalam bidang speech recognition, seperti dijelaskan oleh Lawrence R. Rabiner dalam laporannya yang berjudul "A Tutorial on Hidden Markov Models and Selected Applications in Speech Recognition”

Dalam penelitian ini bagaimana menentukan pola kesesuaian dari setiap pola kata yang di ucapka oleh penyandang Tuna Rungu. Di harapkan Pada penelitian pengenalan pola suara penyandang Tuna Rungu ini ada beberapa tahap metode yang akan di lakukan

1. Penerimaan data input suara

2. Ekstraksi, yaitu penyimpanan data sumber suara penyandang Tuna Rungu sebagai inputan data.

3. Pembandingan / pencocokan, yaitu tahapan pencocokan dari berbagai macam sampel suara yang di kumpulkan.

4. Validasi identitas bentuk dari suara yang di hasilkan 
Secara umum dalam prose pengenalan suara menilai sinyal suara yang masuk dan menyimpannya dalam bentuk digital. Dari proses digitalisasi tersebut kemudian dikonversi dalam bentuk spektrum suara yang akan dianalisa dengan membandingkannya dengan template suara pada database suara dalam. Sebelumnya, data suara masukan dipilah-pilah dan diproses satu per satu berdasarkan setiap kategori suara yang telah di dapat dari para penyandang Tuna Rungu. Pemilahan ini dilakukan agar proses analisis dapat dilakukan secara parallel di sesuaikan dengan tingkat akurasi kesesuaian jenis suara yang di hasilkan. Proses yang pertama kali dilakukan ialah memproses gelombang kontinu spektrum suara ke dalam bentuk diskrit. Pada proses kalkulasi suara dapat di olah ke dalam beberapa proses antara lain :

1. Melakukan Transformasi gelombang suara diskrit menjadi array data.

2. Untuk masing-masing elemen pada data suara di lakukan penghitungan dari ketinggian gelombang (frekuensi) suara yang di hasilkan

\section{PENGUJIAN DAN ANALISA}

Pada saat mengkonversi gelombang suara ke dalam bentuk diskrit, gelombang diperlebar dengan cara memperinci berdasarkan waktu. Hal ini dilakukan agar proses algoritma selanjutnya (pencocokan) lebih mudah dilakukan. Dari tiap elemen array data tersebut, dikonversi ke dalam bentuk bilangan biner. Data biner tersebut yang nantinya akan dibandingkan dengan template data suara yang ada.

Pendekatan sistem yang digunakan adalah sebagai berikut:

1. Pembahasan masalah ditekankan pada segi pengolahan sinyal digital dan pengenalan pola suara anak tuna rungu

2. jumlah koefisien observasi sebanyak 100 sampel data pola suara anak normal dan pola suara anak tuna rungu

3. Metode yang digunakan untuk analisa dan pemodelan Linear Predictive Coding (LPC), Fast Fourier Transform (FFT) dan Jaringan Syaraf Tiruan (JST) dengan dan di mungkinkan untuk mendapatkan metode baru untuk pengenalan pola suara anak tuna runggu

4. Penerimaan data berupa input pola suara anak normal dan anak tuna rungu

5. Ekstraksi, yaitu penyimpanan data sumber suara anak Tuna Rungu sebagai inputan data

6. Pembandingan / pencocokan, yaitu tahapan pencocokan dari berbagai macam sampel suara yang di kumpulkan antara pola suara anak tuna rungu dan pola suara anak normal.

7. Validasi identitas bentuk dari suara yang di hasilkan mencari nilai kecocokan yang paling mendekati pola suara anak normal

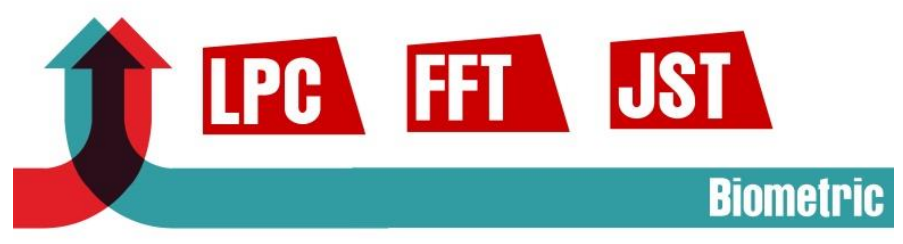

Gambar 4. Diagram Blok Sistem

Proses komunikasi yang dilakukan pada anak normal dapat berjalan sesuai dengan apa yang disampaikan sehingga satu sama lain dapat mengerti tentang pesan yang disampaikan, berbeda dengan proses komunikasi pada anak terbelakang mental/tunagrahita dalam berkomunikasi dengan anak cacat mental/tunagrahita kita perlu memiliki strategi dalam berkomunikasi sehingga anak terbelakang mental/tunagrahita dapat mengerti/paham terhadap pesan yang disampaikan oleh komunikator. Komunikasi merupakan kegiatan yang tidak dapat dipisahkan dari kehidupan manusia. Dapat dikatakan komunikasi merupakan kebutuhan hakiki bagi kehidupan manusia. Banyak orang berpendapat bahwa 
salah satu alasan mengapa kita berkomunikasi adalah untuk memperoleh informasi dan mengetahui terhadap suatu yang menarik perhatian kita, sekaligus berinteraksi dengan orang lain. Gangguan perkembangan artikulasi meliputi kegagalan mengucapkan satu huruf sampai beberapa huruf. Sering terjadi penghilangan atau penggantian bunyi huruf itu sehingga menimbulkan kesan bahwa bicaranya seperti anak kecil. Selain itu juga dapat berupa gangguan dalam pitch, volume atau kualitas suara.[5] Afasia yaitu kehilangan kemampuan untuk membentuk kata-kata atau kehilangan kemampuan untuk menangkap arti kata kata sehingga pembicaraan tidak dapat berlangsung dengan baik.

\section{KESIMPULAN}

1. Hasil pengenalan pola suara anak tuna rungu menggunakan metode biometrik dapat juga menggunakan metode lain yang relevan yang masih bisa berhubungan

2. Tingkat akurasi dari pengenalan pola suara anak tuna runggu setelah di bandingkan dengan pola suara anak normal bisa di dapatkan nilai kesesuaian pola suara yang mendekati

\section{DAFTAR PUSTAKA}

[1] Hallahan, D. P., \& Kauffman, J. M. (2006). Exceptional Learners Introduction to Special Education Tenth Edition. Boston: Pearson.

[2] Paul, P. V., \& Whitelaw, G. M. (2011). Hearing and Deafness. Massachusetts: Jones and Bartlett Publishers.

[3] Beaufays, H. Bourlard, H. Franco, and N. Morgan, "Speech recognition technology," in Handbook of Brain Theory and Neural Networks, 2nd ed., M. Arbib, Ed. Cambridge, MA: MIT Press, 2002.

[4] X. D. Huang, A. Acero, and H. Hon, Spoken Language Processing. Englewood Cliffs, NJ: Prentice-Hall, 2001.

[5] F. Jelinek, Statistical Methods for Speech Recognition. Cambridge, MA: MIT Press, 1997.

[6] L. Rabiner and B. Juang, Fundamentals of Speech Recognition. Englewood Cliffs, NJ: PrenticeHall, 1993.

[7] Levine A, Codina C, Buckley D, De Sousa G, Baseler H. Differences in primary visual cortex predict performance in local motion detection in deaf andhearing adults. National Center for Biotechnology Information, U.S. National Library of Medicine 2015

[8] Moradi S, Lidestam B, Hällgren M, Rönnberg J. Gated auditory speech perception in elderly hearing aid users and elderly normal-hearingindividuals: effects of hearing impairment and cognitive capacity. Trends Hear. 2014 Jul 31

[9] Conway CM, Deocampo JA, Walk AM, Anaya EM, Pisoni DB. Deaf children with cochlear implants do not appear to use sentence context to help recognize spoken words. J Speech Lang Hear Res. 2014 Dec 